\title{
Ring chromosome 4 syndrome
}

INSERM

\section{Source}

INSERM. (1999). Orphanet: an online rare disease and orphan drug data base. Ring chromosome 4 syndrome. ORPHA:1447

Ring chromosome 4 syndrome is an autosomal anomaly characterized by variable clinical features, most commonly including significant intrauterine and postnatal growth retardation, developmental delay, intellectual disability, microcephaly, and dysmorphic facial features. Some less frequent features are cleft lip and/or cleft palate, congenital cardiovascular, gastrointestinal and genitourinary system anomalies. 